\title{
Intraluminal injection of indigo carmine facilitates identification of the afferent limb during double- balloon ERCP
}

Double-balloon endoscopy facilitates endoscopic retrograde cholangiopancreatography (ERCP) in patients with a Roux-en-Y anastomosis [1]. However, it is difficult to identify the afferent limb during double-balloon ERCP [2]. According to retrospective data from February 2007 to January 2009, the rate of accurate identification was $50 \%(14 / 28)$. We report a useful technique to identify the afferent limb of the Roux-en-Y anastomosis during double-balloon ERCP.

In the second portion of the duodenum or at the distal site of the esophagojejunostomy, after inflation of a balloon at the tip of the endoscope to prevent backflow, $50 \mathrm{ml}$ of $0.2 \%$ indigo carmine was injected into the lumen using the accessory channel ( Fig. 1). At the Roux-en-Y site, we evaluated the inflow of indigo carmine into both limbs and identified the limb with less inflow as the afferent limb (๑ Fig. 2).

Between February 2009 and September 2011, this technique was used and evaluated prospectively in 52 consecutive patients with a Roux-en-Y anastomosis. Of the 52,11 patients were excluded because of the following: unrecognized Roux-en-Y in 3 , inaccessible Roux-en-Y in 2 , and no indigo carmine at the Roux-en-Y in 6 . In 33 of the remaining 41 patients (80\%), the afferent limb was accurately identified. In 5 patients, identification was difficult because the amount of inflow was similar in both limbs. In 3 patients, the identification was incorrect.

This technique is based on the theory that little indigo carmine will flow into the afferent limb, but the dye will easily flow into the efferent limb by peristalsis. Double-balloon ERCP is usually performed with the patient in the left lateral position. In some patients, the influence of gravity on the inflow of indigo carmine made identification of the afferent limb difficult or led to incorrect identification.

Intraluminal injection of indigo carmine facilitates identification of the afferent limb during double-balloon ERCP in patients with a Roux-en-Y anastomosis.
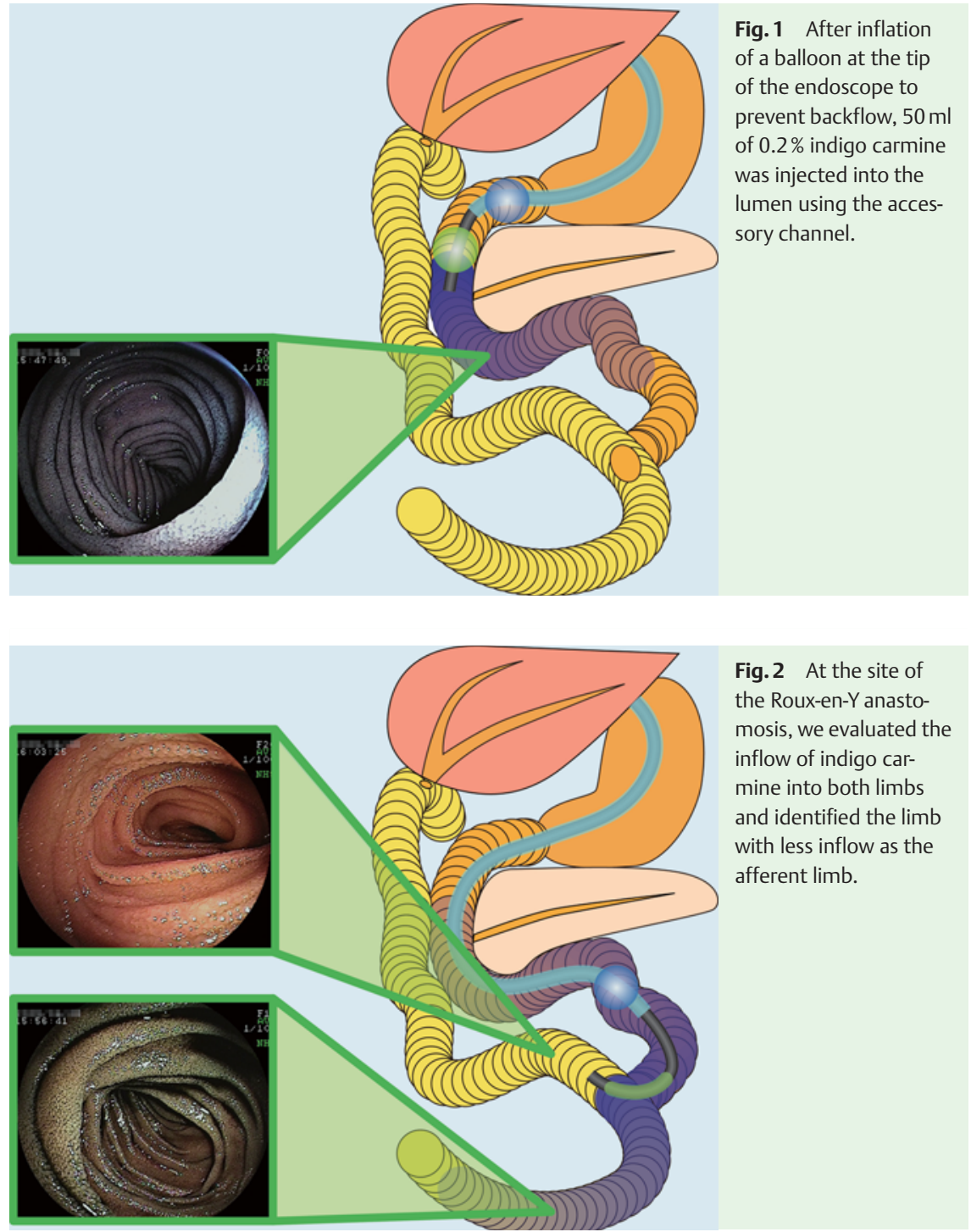

Endoscopy_UCTN_Code_TTT_1AR_2AK

Competing interests: Yamamoto has applied for a patent in Japan for the doubleballoon system described in the article. All other authors disclosed no financial relationships relevant to this publication.

T. Yano, H. Hatanaka, H. Yamamoto, K. Nakazawa, N. Nishimura, S. Wada, K. Tamada, K. Sugano

Department of Medicine, Division of Gastroenterology, Jichi Medical University, Shimotsuke, Tochigi, Japan

\section{Acknowledgments $\nabla$}

We thank Professor Alan Lefor of the Department of Surgery at Jichi Medical University for language editing of the manuscript. 


\section{References}

1 Haruta H, Yamamoto H, Mizuta Ket al. A case of successful enteroscopic balloon dilation for late anastomotic stricture of choledochojejunostomy after living donor liver transplantation. Liver Transpl 2005; 11: 1608 1610

2 Shimatani M, Matsushita M, Takaoka M et al. Effective "short" double-balloon enteroscope for diagnostic and therapeutic ERCP in patients with altered gastrointestinal anatomy: a large case series. Endoscopy 2009; 41: 849-854
Bibliography

DOI http://dx.doi.org/

10.1055/s-0032-1309865

Endoscopy 2012; 44: E340-E341

(c) Georg Thieme Verlag KG

Stuttgart · New York

ISSN 0013-726X
Corresponding author

T. Yano, MD, PhD

Department of Medicine Division of Gastroenterology jichi Medical University

3311-1 Yakushiji, Shimotsuke Tochigi 329-0498

Japan

Fax: +81-285-44-8297

tomonori@jichi.ac.jp 